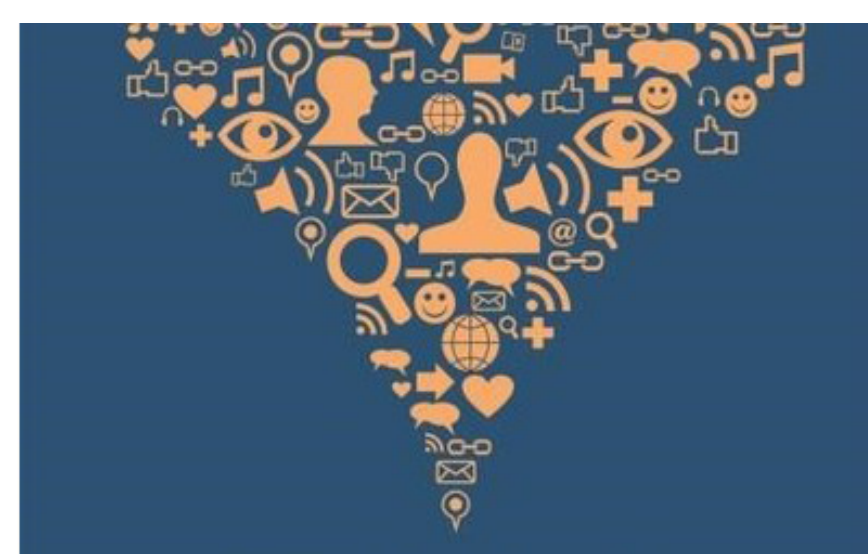

Bianca Marder Dreyer

\section{Relações públicas na contemporaneidade}

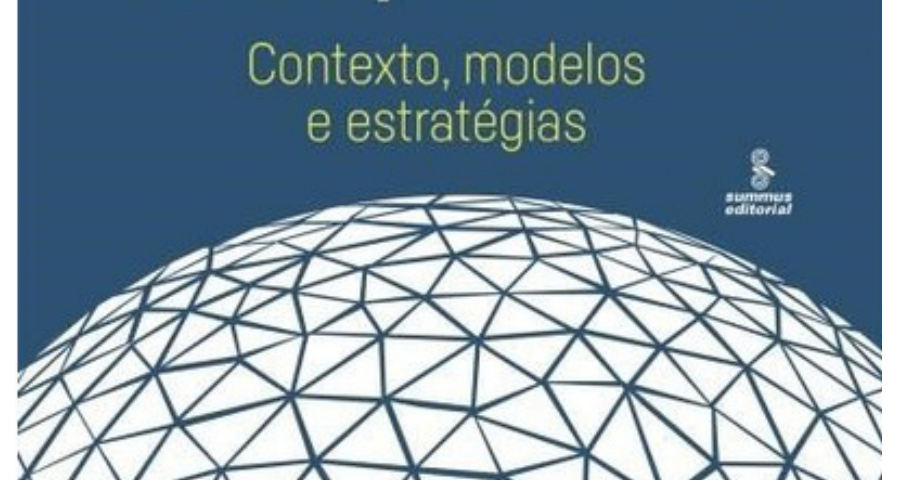

\section{Bianca Marder Dreyer}

Relações públicas na contemporaneidade: contexto, modelos e estratégias

Summus Editorial

São Paulo, 2017

$160 \mathrm{p}$.

Else Lemos

- Doutora e mestre em Ciências da Comunicação pela Escola de Comunicações e Artes da Universidade de São Paulo (ECA-USP)

- Graduada em Comunicação Social - Relações Públicas pela Universidade Federal de Goiás (UFG)

- Especialista em Gestão Estratégica em Comunicação Organizacional e Relações Públicas e em Gestão da Comunicação Digital pela ECA-USP

- Docente nos cursos de especialização Gestcorp e Digicorp, da ECA-USP

- Professora Adjunta na Faculdade Cásper Líbero (Facásper)

- E-mail: else_lemos@uol.com.br 


\title{
Relações públicas, amálgama para a gestão de relacionamentos na era da visibilidade
}

\author{
Public relations, amalgam for relationships \\ management in the era of visibility
}

\section{Relaciones públicas, amalgama para la gestión de relaciones en la era de la visibilidad}

$\mathrm{H}$ á cerca de três décadas vemos a disciplina de relações públicas buscando estabelecer vínculos, ora bem-sucedidos, ora nem tanto, com os estudos da administração e da chamada escola de comunicação estratégica, ligada ao business management. Em muitos casos, porém, esse esforço se deu em detrimento do termo "relações públicas", abrindo-se espaço para expressões como "gerenciamento da comunicação organizacional" ou "gerenciamento estratégico da comunicação organizacional", apenas para mencionar alguns dos termos adotados na pesquisa e na literatura da área.

Em Relações públicas na contemporaneidade: contexto, modelos e estratégias, Bianca Marder Dreyer faz de relações públicas termo-chave que dá sentido e caracteriza a comunicação organizacional contemporânea. 0 trabalho, resultante de sua dissertação de mestrado em Ciências da Comunicação (ECA-USP), busca nos fundamentos teórico-conceituais de relações públicas as interfaces para o diálogo com outras disciplinas, propondo uma visão alinhada ao espírito do tempo e às demandas de um mundo hiperconectado em contínua mudança.

Já na introdução, a pesquisadora estabelece o foco de sua análise: a mudança na forma como as organizações constroem os relacionamentos com seus públicos no contexto de uma sociedade na qual a comunicação tem papel central e o digital deve ser transversal às estratégias de comunicação nas organizações. Se, por um lado, as relações públicas podem ser entendidas segundo suas definições pioneiras, por outro, suas práticas solicitam um olhar trans, ou seja, para além de suas fronteiras, em coadjuvação com outras disciplinas, algumas das quais tão jovens quanto relações públicas e em desenvolvimento exponencial, como é o caso da inteligência artificial, por exemplo.

0 texto, didático e construído com exímia linearidade e responsabilidade histórica - a cada capítulo há uma breve explicação sobre os temas que serão discutidos e, quando necessário, resgate de fatos e datas que merecem atenção -, estabelece alguns pressupostos que devem ser observados ao se pensar em planejamento de comunicação. Assim, indica que, antes de tudo, quem trabalha com comunicação deve conhecer e estar atento a temas contemporâneos que explicam a sociedade 
em que vivemos. Nesse sentido, a autora se debruça sobre três conceitos centrais - sociedade em rede, da transparência e do espetáculo -, assinalando as imbricações entre indivíduos, organizações e sistemas de mídia, bem como a exacerbação da exposição e da comunicação em tempo real.

A ideia de que informação é a matéria-prima da comunicação se destaca na obra. Essa noção, base fundamental para 0 desenvolvimento disciplinar de relações públicas, reitera o pressuposto de que as relações públicas mantêm sua essência, mas são desafiadas, hoje, pelas novas configurações comunicacionais, computacionais e digitais.

Um tema que ganha uma perspectiva autoral é a discussão sobre públicos, pois a obra propõe uma classificação que considera o público presente no digital como ubíquo. Segundo a autora, o 'público ubíquo' é conectado, ativo, produtor de conteúdo, protagonista de comunicação e em constante deslocamento. Com o desenvolvimento da web 3.0 e 4.0, Dreyer indica que a atividade de relações públicas já está inserida e sujeita a esses ambientes, e, portanto, o planejamento de relações públicas deve levar em consideração essa nova realidade.

A obra traz, ainda, o exame detalhado de treze modelos de comunicação e dois modelos de negócios. Embora os conceitos, modelos e propostas analisados partam de estruturas e conceituações disciplinarmente distintas, a opção por nomear essas representações como "modelos" se mostra útil aos que buscam uma visão mais prática e aplicável ao dia a dia profissional. Essa seção traz um resgate de conceitos e modelos já mencionados em diversas obras da área, como os clássicos modelos de relações públicas e o conceito de comunicação integrada. A autora, porém, não se contenta em agrupar esses assuntos já tradicionalmente estudados na área; antes, busca reconstituir o percurso de cada uma dessas conceituações, reinterpretandoas. Além disso, agrega conceitos e modelos discutidos no âmbito dos estudos de mídia, administração e business management, contextualizando-os ao planejamento de relações públicas.

Por fim, a obra apresenta características e pressupostos da interação e da visibilidade no cenário contemporâneo, indicando que estabelecer laços dialógicos baseados em interação mútua é o cenário ideal para os relacionamentos entre organizações e públicos. Uma vez que a presença marcante dos públicos nas redes, hoje, traz novas formas de visibilidade para as organizações, por isso mesmo devem buscar no planejamento estratégico as bases para o gerenciamento dos relacionamentos.

A linha de pesquisa que vincula relações públicas e comunicação estratégica tem ganhado importância nas últimas décadas em âmbito global, e o trabalho de Bianca Dreyer é um sopro de renovação para a escola brasileira de relações públicas. A pesquisadora demonstra forte compromisso com leitura abrangente do campo (e de outros) e conhecimento apurado de diferentes abordagens que podem sustentar o planejamento de comunicação e relações públicas. Com linguagem e estilo marcantes, e diversas figuras e infográficos que resumem ou ilustram os conceitos explorados no texto, revela zelo conceitual e seu vigoroso caráter pedagógico, sendo leitura indicada e útil para estudantes, professores e profissionais de mercado. 